\title{
Sustained release enteric coated tablets of pantoprazole: Formulation, in vitro and in vivo evaluation
}

\author{
BARNABAS WILSON ${ }^{1, *}$ \\ PATEL PRITESH BABUBHAI ${ }^{1}$ \\ MOOTHANDASSERY SANKARAKUTTY SAJEEV 2 \\ JOSEPHINE LENO JENITA ${ }^{1}$ \\ S. R. BRAHMANI PRIYADARSHINI ${ }^{1}$ \\ 1 Department of Pharmaceutics \\ Dayananda Sagar College of Pharmacy \\ Kumaraswamy Layout \\ Bangalore-560078, India \\ ${ }^{2}$ Division of Crop Utilization and \\ Biotechnology \\ Central Tuber Crops Research Institute \\ Sreekariyam, Trivandrum-695017, India
}

\begin{abstract}
In this study, an attempt was made to deliver pantoprazole in a sustained manner using delayed release tablets. The tablets were prepared by the wet granulation method using HPMC, cassava starch and polyvinyl pyrrolidine as polymers, Avicel PH 102 (MCC) as filler and potato starch as binder. The prepared tablets were evaluated for hardness, mass variation, friability and drug content uniformity, and the results were found to comply with official standards. The prepared tablets were coated using an enteric coating polymer such as cellulose acetate phthalate, Eudragit L100 and drug coat L100 by the dip coating method. The in vitro release was studied using $\mathrm{pH}$ 1.2 acidic buffer and $\mathrm{pH} 6.8$ phosphate buffer and the study revealed that the prepared tablets were able to sustain drug release into the intestine. The anti-ulcer activity was evaluated by a water immersion stress induced ulcer model. The enteric coated pantoprazole tablets significantly reduced ulcer formation.
\end{abstract}

Keywords: pantoprazole, delayed release tablets, ulcer

Ulcers, crater-like sores, formed in the stomach and duodenum are called gastric and duodenal ulcers, respectively. Stomach and duodenum ulcer are generally referred to as peptic ulcers. Helicobacter pylori infection is the major cause of peptic ulcer, since 85 to $95 \%$ of patients with peptic ulcer have this organism (1). Non-steroidal anti-inflammatory drugs such as aspirin can also cause or worsen ulcer (2). Pantoprazole, a proton pump inhibitor, which belongs to the benzimidazole groups, is used for the treatment of peptic ulcer. Pantoprazole inhibits gastric acid by blocking the $\mathrm{H}^{+} / \mathrm{K}^{+}$-adenosine triphosphatase enzyme system (the proton pump) of gastric parietal cells (3). Pantoprazole undergoes degradation at a low $\mathrm{pH}$ of the esophagus and stomach; it is therefore given as enteric-coated tablets. The enteric coating dissolves only at alkaline $\mathrm{pH}$, thus preventing drug degradation in acidic environment of the stomach (4). The therapeutic concentration of a drug in blood can be maintained for a prolonged period of time by admini-

\footnotetext{
* Correspondence; e-mail: antrilparavai@gmail.com
} 
stering it in the form of a sustained release dosage form. Amongst sustained release formulations, sustained release tablet dosage forms have become extremely popular in modern therapeutics. Drugs with short half-lives are ideal candidates for sustained drug delivery (5). Many drugs have been marketed as sustained release tablets owing to their cost effectiveness and greater patient compliance. In the present study, we made an attempt to deliver pantoprazole in a sustained manner using delayed release tablets and studied their effectiveness for treating ulcer in a water immersion stress induced animal model.

\section{EXPERIMENTAL}

\section{Materials}

Pantoprazole was a gift from Alembic Pharma, Baroda, India. The polymers, hydroxypropylmethylcellulose (HPMC) and polyvinyl pyrrolidone (PVP) were purchased from SD Fine Chem. Ltd., India. Cassava starch was obtained from Central Tuber Crops Research Institute, India. Cellulose acetate phthalate (CAP), drug coat L100 (methacrylic acid copolymer), Eudragit L100 and microcrystalline cellulose (Avicel PH 102) were obtained as a gift from Strides Arco Lab., India. All other chemicals used for the study were of analytical grade.

\section{Preparation of sustained release tablets}

Pantoprazole tablets were prepared by the wet granulation method (6). Specified quantity of pantoprazole, hydroxypropylmethylcellulose, cassava starch and polyvinyl pyrrolidone and Avicel PH 102 were weighed according to the formula given in Table I and transferred into a mortar with pestle and mixed thoroughly. The powder mass was mixed with a $5 \%$ starch paste to obtain a sluggy mass, which was passed through a sieve with aperture pore of $1.4 \mathrm{~mm}$ to obtain granules. The granules prepared were dried at 40 ${ }^{\circ} \mathrm{C}$ for $4 \mathrm{~h}$. The dried granules were screened through sieves of $0.71 \mathrm{~mm}$ and $0.355 \mathrm{~mm}$ and stored for further studies. Required quantities of magnesium stearate and talc were finally added and mixed thoroughly. The mixture was directly punched into tablets weighing about $200 \mathrm{mg}$ (containing $40 \mathrm{mg}$ of pantoprazole), using a rotary tablet compression machine (12 stations, Karnavati, India), and 8-mm diameter concave punches. The different batches of pantoprazole tablets were collected and stored in airtight containers.

\section{Evaluation of granules}

Size analysis by optical microscopy. - Dry granules were uniformly spread on a glass slide. Granule particle size was measured along the longest and the shortest axes (cross shaped measurement) using an optical microscope (Olympus CH20i, India) after calibration. Average of these two readings is given as the mean diameter of particles. The diameter of at least 50 granules in each batch was determined.

Bulk density, tapped density and Carr's index. - Bulk density is the ratio of the total mass of powder to the bulk volume of powder. It was measured by pouring weighed powder into a graduated measuring cylinder and the volume was noted. Tapped density is the ratio of the total mass of powder to the tapped volume of powder. Tapped 
B. Wilson et al.: Sustained release enteric coated tablets of pantoprazole: Formulation, in vitro and in vivo evaluation, Acta Pharm. 63 (2013) 131-140.

Table I. Formula for the preparation of pantoprazole tablets

\begin{tabular}{|c|c|c|c|c|c|c|c|c|}
\hline \multirow[b]{2}{*}{ Batch } & \multicolumn{8}{|c|}{ Ingredient $^{\mathrm{a}}$} \\
\hline & $\begin{array}{l}\text { Pantoprazole } \\
\text { (mg) }\end{array}$ & $\begin{array}{l}\text { HPMC } \\
(\mathrm{mg})\end{array}$ & $\begin{array}{c}\text { Cassava } \\
\text { starch } \\
(\mathrm{mg})\end{array}$ & $\begin{array}{l}\text { PVP } \\
\text { (mg) }\end{array}$ & $\begin{array}{l}\text { Avicel } \\
\text { PH } 102 \\
\text { (mg) }\end{array}$ & $\begin{array}{l}\text { Starch } \\
\text { paste } \\
(5 \%)\end{array}$ & $\begin{array}{l}\text { Talc } \\
(\mathrm{mg})\end{array}$ & $\begin{array}{l}\text { Magnesium } \\
\text { stearate } \\
(\mathrm{mg})\end{array}$ \\
\hline F1 & 40 & - & - & - & 154 & q.s. & 2 & 4 \\
\hline F2 & 40 & 20 & - & - & 134 & q.s. & 2 & 4 \\
\hline F3 & 40 & 40 & - & - & 114 & q.s. & 2 & 4 \\
\hline $\mathrm{F} 4$ & 40 & 60 & - & - & 94 & q.s. & 2 & 4 \\
\hline F5 & 40 & 80 & - & - & 74 & q.s. & 2 & 4 \\
\hline F6 & 40 & 100 & - & - & 54 & q.s. & 2 & 4 \\
\hline F7 & 40 & - & 20 & - & 134 & q.s. & 2 & 4 \\
\hline F8 & 40 & - & 40 & - & 114 & q.s. & 2 & 4 \\
\hline F9 & 40 & - & 60 & - & 94 & q.s. & 2 & 4 \\
\hline F10 & 40 & - & 80 & - & 74 & q.s. & 2 & 4 \\
\hline F11 & 40 & - & 100 & - & 54 & q.s. & 2 & 4 \\
\hline F12 & 40 & - & - & 20 & 134 & q.s. & 2 & 4 \\
\hline F13 & 40 & - & - & 40 & 114 & q.s. & 2 & 4 \\
\hline F14 & 40 & - & - & 60 & 94 & q.s. & 2 & 4 \\
\hline F15 & 40 & - & - & 80 & 74 & q.s. & 2 & 4 \\
\hline F16 & 40 & - & - & 100 & 54 & q.s. & 2 & 4 \\
\hline
\end{tabular}

a Total mass of each tablet: $200 \mathrm{mg}$.

q.s. - quantum satis

volume was measured by tapping the powder to constant volume. Carr's index indicates the powder flow properties. It is expressed in percentage and is given by $\left(D_{\mathrm{t}}-D_{\mathrm{b}} / D_{\mathrm{t}}\right) \times 100$, where $D_{\mathrm{t}}$ is tapped density and $D_{\mathrm{b}}$ is bulk density (7).

Angle of repose. - Angle of repose is the maximum angle possible between the surface of a pile of powder and the horizontal plane. Sufficient quantity of pantoprazole granules was passed through a funnel from a particular height $(2 \mathrm{~cm})$ onto a flat surface until it formed a heap, which touched the tip of the funnel. The height and radius of the heap were measured. The angle of repose $(\theta)$ was calculated using the formula; $\theta=\tan ^{-1}$ $(h / r)$; where, $h$ is the height of the pile in $\mathrm{cm}$ and $r$ is the radius of the pile in $\mathrm{cm}(7)$.

\section{Evaluation of sustained release tablets}

Hardness, friability and mass variation. - The tablets were subjected to a hardness test. It was carried out by using a hardness tester (SECOR, India) and expressed in $\mathrm{kg} \mathrm{cm}^{-2}$. For friability (\%), from each batch, twenty tablets were selected randomly and friability was determined using the Cintex friability test apparatus, India. 20 tablets were randomly selected for mass variation study from each lot and weighed individually, and the average mass was determined. The percent deviation of each tablet's mass from the average mass was calculated according to the official method (8). 
Drug content uniformity. - The drug was extracted completely from the tablets in $\mathrm{pH} 6.8$ phosphate buffer and the solution was filtered. Filtrate $(1 \mathrm{~mL})$ was diluted with $\mathrm{pH} 6.8$ phosphate buffer. Absorbance of the resulting solution was measured with a UV-Visible spectrophotometer UV-1700 (Shimadzu, Japan) at $289 \mathrm{~nm}$.

\section{Enteric coating of compressed tablets}

Preparation of enteric coating solution. - The coating solution was composed of Eudragit L100 or cellulose acetate phthalate or drug coat L100 as an enteric polymer, titanium dioxide as opacifier, diethyl phthalate as plasticizer, and acetone/isopropyl alcohol mixture (1:2) as solvent (Table II). Titanium dioxide was triturated in a glass mortar with a small amount of solvent mixture and filtered through muslin cloth into the polymer solution already prepared with one half of the solvent mixture. Diethyl phthalate was added and the volume made up with the rest of the solvent mixture. Finally, this mixture was constantly stirred for $1 \mathrm{~h}$ using a mechanical stirrer at $1000 \mathrm{rpm}$ and the stirred coating solution was again filtered through muslin cloth.

Enteric coating of pantoprazole compressed tablets by the dipping method. - For enteric coating, batches F3, F9 and F15 were selected based on their physicochemical characteristics and release profile, and hereafter they are referred to as ECF3, ECF9 and ECF15, respectively. The compressed tablets were coated with the enteric coating solution (composition is given above) by the dipping method. Coating was continued till the required mass gain was achieved. The coated tablets were studied for their mass variation, thickness, uniformity of drug content and in vitro dissolution. Enteric coating films were also prepared by pouring an aliquot amount of solution onto Petri plates and dried at room temperature.

Physicochemical evaluation of coating films. - The dried enteric coating polymer films were cut into $1-\mathrm{cm}^{2}$ pieces and evaluated for their thickness, mass and solubility. The thickness of dried films was determined by a Vernier caliber. Film solubility was studied at $\mathrm{pH} 1.2$ and 6.8 . The $1 \times 1 \mathrm{~cm}$ coating film was selected, weighed and transferred into a beaker containing $20 \mathrm{~mL}$ of specified $\mathrm{pH}$ medium, which was stirred for $1 \mathrm{~h}$ at $37 \pm 1^{\circ} \mathrm{C}$ and finally film solubility was measured.

In vitro drug release. - A USP dissolution apparatus type II/10 (USP XXIII) was employed to study the in vitro drug release from various batches. The dissolution medium used was $900 \mathrm{~mL}$ of acidic buffer of $\mathrm{pH} 1.2$ for $2 \mathrm{~h}$ and phosphate buffer of $\mathrm{pH} 6.8$ for $10 \mathrm{~h}$. The temperature was maintained at $37 \pm 0.5{ }^{\circ} \mathrm{C}$ and the stirring rate was $100 \mathrm{rpm}$.

Table II. Coating solution composition

\begin{tabular}{lc}
\hline \multicolumn{1}{c}{ Ingredient } & Content $(\%, \mathrm{~m} / \mathrm{m})$ \\
\hline Cellulose acetate phthalate/Eudragit L100/drug coat L100 & 6.0 \\
Titanium dioxide & 2.6 \\
Diethyl phthalate & 2.0 \\
Acetone & 59.4 \\
Isopropyl alcohol & 30.0 \\
\hline
\end{tabular}


Samples $(2 \mathrm{~mL})$ were withdrawn at regular time intervals and the same volume was replaced with fresh dissolution medium. The samples were measured for drug content at $284 \mathrm{~nm}(\mathrm{pH}$ 1.2) and at $289 \mathrm{~nm}(\mathrm{pH}$ 6.8) against blank.

Release kinetics. - The in vitro release data of selected formulations (ECF3, ECF9 and ECF15 coated with cellulose acetate phthallate) were fitted to various kinetic equations such as zero order, first-order, Higuchi and Korsmeyer-Peppas (11). For zero-order $(Q=$ $\left.Q_{0}-k_{0} t\right)$, the graph was plotted for cumulative percent of drug released vs. time, first order release (ln $\left.Q=\ln Q_{0}-k_{1} t\right)$ graph was plotted in log cumulative percent of drug remaining vs. time; In the case of Higuchi $\left(Q=k_{\mathrm{H}} t^{1 / 2}\right)$, the graph was plotted as cumulative percent of drug released vs. square root of time, and for Korsmeyer-Peppas $\left(Q / Q_{0}\right.$ $=k t^{\mathrm{n}}$ ) the graph was plotted as log cumulative percent of drug released vs. log time. $k_{0}$, $k_{1}$ and $k_{2}$ are release rate constants, $Q / Q_{0}$ is the fraction of drug released at time $t$, and $n$ is the diffusional release exponent, which is used to find out the drug release mechanism. If the value of $n$ is equal up to 0.5 , the drug is released with a Fickian diffusion mechanism, if $n$ is in between 0.5 to 1.0, it indicates a non-Fickian or anomalous drug release, whereas, $n$ is 1.0 for zero-order release (11)

Stability studies. - For stability studies, the ECF3 tablets were stored at room temperature and $40{ }^{\circ} \mathrm{C}$ (RH $75 \%$ ) over a period of 1 month (7). Samples were evaluated after 10, 20 and 30 days for different parameters such as physical appearance, hardness, mass variation, drug content and dissolution.

\section{In vivo studies}

Animals. - Albino rats of Wistar strain of either sex weighing between 150-200 g were obtained from the animal house of the Dayananda Sagar College of Pharmacy, Bangalore, India, after getting approval by the Dayananda Sagar College of Pharmacy's Animal Ethics Committee of the same institution. The studies were performed in accordance with the CPCSEA guidelines. The animal house was well ventilated and the animals were maintained at a 12:12 h light/dark cycle in large spacious cages throughout the experimental period. They were given free access to food and water. All efforts were made to minimize animal suffering.

Evaluation of antiulcer activity. - The antiulcer activity of the pantoprazole tablets enteric coated with CAP (ECF3) was evaluated using a water immersion stress induced ulcer model (12). This is a simple method and the lesions produced by this model are located in the glandular region of the stomach. The animals were divided into three groups of six animals each. Group I was vehicle control, group II was stress control and group III was treatment control and received the pantoprazole coated tablet formulation (ECF3) at a dose level of $10 \mathrm{mg} \mathrm{kg}^{-1}$ body mass for 7 days prior to subjecting them to stress. The animals were deprived of food for $24 \mathrm{~h}$ before experimentation, but had free access to drinking water. After the treatment, the animals were made to swim in water at $25 \pm 1{ }^{\circ} \mathrm{C}$ for $5 \mathrm{~h}$. After $5 \mathrm{~h}$ of swimming, the animals were anaesthetized and the stomach of each animal was opened and examined with a hand lens for the extent of ulceration. The ulcerogenic indices were determined using the following scoring system: shedding of epithelium $=10$, petichial and frank haemorrhages $=20$, one or two ulcers $=30$, many ulcers $=40$ and perforated ulcers $=50$. The score of the treated group was compared with the stress control group. 
B. Wilson et al.: Sustained release enteric coated tablets of pantoprazole: Formulation, in vitro and in vivo evaluation, Acta Pharm. 63 (2013) 131-140.

\section{RESULTS AND DISCUSSION}

\section{Preparation of pantoprazole tablets}

Pantoprazole tablets were prepared by the wet granulation method. In this study, tablets were prepared using HPMC, cassava starch and PVP as hydrophilic release retarding polymers in different concentrations (Table I). During optimization of the granules, low moisture sluggy masses were found to have more fines and high friability and the high moisture sluggy masses were sticky in the sieving process. Hence, optimum moisture (paste $5 \%$ ) was used for preparing the granules. This method produced narrow shaped granular particles with very low fines. The obtained granules were smooth and almost uniformly sized.

\section{Characterization of pantoprazole tablets}

Precompression and post compression parameters. - Pantoprazole granules were evaluated for their yield, granule particle size, angle of repose, bulk density, tapped density and compressibility and the results are given in Table III. The yield of granules ranged between 86 and $98 \%$. This could be considered a satisfactory yield value and was due to

Table III. Physicochemical evaluation of pantoprazole granules

\begin{tabular}{ccccccc}
\hline & \multicolumn{5}{c}{ Parameter } \\
\cline { 2 - 7 } Batch & $\begin{array}{c}\text { Yield } \\
(\%)^{\mathrm{a}}\end{array}$ & $\begin{array}{c}\text { Mean } \\
\text { particle size } \\
(\mathrm{mm})^{\mathrm{b}}\end{array}$ & $\begin{array}{c}\text { Bulk } \\
\text { density } \\
\left(\mathrm{g} \mathrm{mL}^{-1}\right)^{\mathrm{a}}\end{array}$ & $\begin{array}{c}\text { Tapped } \\
\text { density } \\
\left.(\mathrm{g} \mathrm{mL})^{-1}\right)^{\mathrm{a}}\end{array}$ & $\begin{array}{c}\text { Carr's } \\
\text { index } \\
(\%)^{\mathrm{a}}\end{array}$ & $\begin{array}{c}\text { Angle } \\
\text { of repose } \\
\left({ }^{\circ}\right)^{\mathrm{a}}\end{array}$ \\
\hline F1 & $97.82 \pm 1.85$ & $0.498 \pm 0.05$ & $0.306 \pm 0.03$ & $0.326 \pm 0.03$ & $6.13 \pm 0.12$ & $25.79 \pm 0.24$ \\
F2 & $94.85 \pm 0.94$ & $0.545 \pm 0.12$ & $0.312 \pm 0.04$ & $0.335 \pm 0.02$ & $6.86 \pm 0.15$ & $26.95 \pm 0.15$ \\
F3 & $95.37 \pm 1.61$ & $0.527 \pm 0.06$ & $0.358 \pm 0.05$ & $0.385 \pm 0.04$ & $7.01 \pm 0.13$ & $26.33 \pm 0.17$ \\
F4 & $94.12 \pm 2.05$ & $0.542 \pm 0.05$ & $0.357 \pm 0.03$ & $0.384 \pm 0.05$ & $7.03 \pm 0.09$ & $28.31 \pm 0.26$ \\
F5 & $93.43 \pm 0.89$ & $0.533 \pm 0.21$ & $0.359 \pm 0.04$ & $0.394 \pm 0.03$ & $8.88 \pm 0.24$ & $27.20 \pm 0.14$ \\
F6 & $91.68 \pm 1.44$ & $0.535 \pm 0.06$ & $0.384 \pm 0.04$ & $0.429 \pm 0.05$ & $10.48 \pm 0.20$ & $30.27 \pm 0.34$ \\
F7 & $94.23 \pm 1.79$ & $0.512 \pm 0.04$ & $0.312 \pm 0.03$ & $0.334 \pm 0.06$ & $6.58 \pm 0.14$ & $29.52 \pm 0.14$ \\
F8 & $95.89 \pm 1.90$ & $0.548 \pm 0.11$ & $0.286 \pm 0.05$ & $0.313 \pm 0.04$ & $8.62 \pm 0.07$ & $26.13 \pm 0.26$ \\
F9 & $97.14 \pm 1.79$ & $0.536 \pm 0.05$ & $0.306 \pm 0.03$ & $0.334 \pm 0.05$ & $8.38 \pm 0.17$ & $26.78 \pm 0.18$ \\
F10 & $94.42 \pm 1.18$ & $0.559 \pm 0.12$ & $0.294 \pm 0.05$ & $0.324 \pm 0.03$ & $9.25 \pm 0.23$ & $28.09 \pm 0.21$ \\
F11 & $93.57 \pm 0.94$ & $0.538 \pm 0.06$ & $0.307 \pm 0.02$ & $0.340 \pm 0.03$ & $9.70 \pm 0.18$ & $28.74 \pm 0.36$ \\
F12 & $94.60 \pm 1.45$ & $0.507 \pm 0.04$ & $0.384 \pm 0.02$ & $0.406 \pm 0.06$ & $5.41 \pm 0.32$ & $25.47 \pm 0.12$ \\
F13 & $94.86 \pm 2.34$ & $0.537 \pm 0.05$ & $0.394 \pm 0.06$ & $0.416 \pm 0.05$ & $5.28 \pm 0.16$ & $28.47 \pm 0.19$ \\
F14 & $96.13 \pm 1.93$ & $0.523 \pm 0.04$ & $0.416 \pm 0.05$ & $0.457 \pm 0.04$ & $8.97 \pm 0.06$ & $29.79 \pm 0.25$ \\
F15 & $97.37 \pm 2.05$ & $0.567 \pm 0.15$ & $0.384 \pm 0.04$ & $0.410 \pm 0.03$ & $6.34 \pm 0.14$ & $26.32 \pm 0.14$ \\
F16 & $86.13 \pm 0.85$ & $0.545 \pm 0.13$ & $0.418 \pm 0.03$ & $0.472 \pm 0.05$ & $11.44 \pm 0.12$ & $30.79 \pm 0.23$ \\
\hline
\end{tabular}

a Mean $\pm \mathrm{SD}, n=3$.

b Mean $\pm \mathrm{SD}, n=50$. 
B. Wilson et al.: Sustained release enteric coated tablets of pantoprazole: Formulation, in vitro and in vivo evaluation, Acta Pharm. 63 (2013) 131-140.

Table IV. Physicochemical evaluation of pantoprazole tablets

\begin{tabular}{cccc}
\hline \multirow{3}{*}{ Batch } & \multicolumn{3}{c}{ Parameter } \\
\cline { 2 - 4 } & Hardness $\left(\mathrm{kg} \mathrm{cm}^{-2}\right)^{\mathrm{b}}$ & Average mass $(\mathrm{g})^{\mathrm{c}}$ & ${\text { Content uniformity }(\%)^{\mathrm{a}}}^{\text {F1 }}$ \\
F2 & $5.40 \pm 0.02$ & $0.201 \pm 0.020$ & $98.85 \pm 0.21$ \\
F3 & $6.20 \pm 0.12$ & $0.199 \pm 0.120$ & $97.71 \pm 0.15$ \\
F4 & $4.90 \pm 0.21$ & $0.204 \pm 0.009$ & $98.85 \pm 0.34$ \\
F5 & $4.93 \pm 0.15$ & $0.203 \pm 0.024$ & $97.42 \pm 0.42$ \\
F6 & $4.73 \pm 0.42$ & $0.208 \pm 0.031$ & $96.85 \pm 0.16$ \\
F7 & $5.66 \pm 0.17$ & $0.205 \pm 0.015$ & $97.14 \pm 0.09$ \\
F8 & $8.20 \pm 0.16$ & $0.199 \pm 0.019$ & $98.55 \pm 0.48$ \\
F9 & $5.60 \pm 0.24$ & $0.209 \pm 0.008$ & $99.42 \pm 0.26$ \\
F10 & $5.73 \pm 0.25$ & $0.198 \pm 0.007$ & $96.85 \pm 0.35$ \\
F11 & $5.12 \pm 0.34$ & $0.203 \pm 0.014$ & $96.28 \pm 0.42$ \\
F12 & $8.06 \pm 0.18$ & $0.206 \pm 0.016$ & $95.78 \pm 0.13$ \\
F13 & $7.66 \pm 0.09$ & $0.198 \pm 0.027$ & $94.57 \pm 0.18$ \\
F14 & $5.56 \pm 0.24$ & $0.207 \pm 0.034$ & $95.42 \pm 0.38$ \\
F15 & $5.83 \pm 0.08$ & $0.206 \pm 0.016$ & $95.71 \pm 0.27$ \\
F16 & $6.21 \pm 0.13$ & $0.204 \pm 0.006$ & $95.71 \pm 0.36$ \\
\hline
\end{tabular}

a Mean $\pm \mathrm{SD}, n=3$.

$\mathrm{b}$ Mean $\pm \mathrm{SD}, n=6$.

${ }^{\mathrm{c}}$ Mean $\pm \mathrm{SD}, n=20$.

polymer binding properties of granules. The particles were found to possess a narrow size distribution range with particle size from $0.50 \pm 0.1$ to $0.58 \pm 0.15 \mathrm{~mm}$. Bulk density of the granules ranged from $0.29 \pm 0.05$ to $0.42 \pm 0.03 \mathrm{~g} \mathrm{~mL}^{-1}$, while tapped densities ranged between $0.31 \pm 0.04$ to $0.47 \pm 0.05 \mathrm{~g} \mathrm{~mL}^{-1}$. The low compressibility values $(5.28 \pm 0.16$ to $11.44 \pm 0.12 \%)$ and angle of repose $\left(25.47 \pm 0.12\right.$ to $\left.30.79 \pm 0.26^{\circ}\right)$ indicate good flowability of the prepared granules, which in turn indicates homogenous filling of the die cavity during tablet compression (7).

Post compression parameters such as hardness, mass variation, content uniformity, friability and in vitro drug release of pantoprazole tablets are given in Table IV. Tablets should have sufficient hardness to withstand handling without breaking or crumbling. Hardness plays a vital role for drug release in the case of sustained release tablets. Average hardness was found in the range of 4.73 to $8.40 \mathrm{~kg} \mathrm{~cm}^{-2}$. Friability of the tablets ranged from 0.01 to $0.11 \%$ which is less than $1 \%$. Drug content uniformity ranged from 94.6 to $99.4 \%$.

Physicochemical evaluation of coating films. - It was found that the enteric coating films of cellulose acetate phthalate, Eudragit L100 and drug coat L100 were completely insoluble at $\mathrm{pH} 1.2$ and soluble at $\mathrm{pH}$ 6.8.

In vitro drug release from compressed tablets and coated tablets. - The in vitro release of pantoprazole from uncoated and coated tablets was studied at $\mathrm{pH} 1.2$ acidic buffer for $2 \mathrm{~h}$ and in phosphate buffer $\mathrm{pH} 6.8$ for $10 \mathrm{~h}$. The varying concentration of HPMC (F1 to F6), 


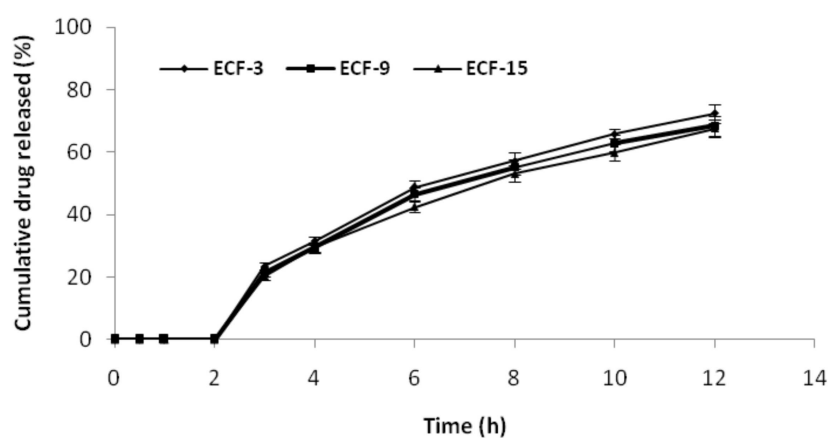

Fig. 1. In vitro release of pantoprazole from CAP coated tablet formulations ECF3, ECF9 and ECF15, Mean $\pm \mathrm{SD}, n=3$.

cassava starch (F7 to F11) and PVP (F12 to F16) in tablet formulations showed a marked difference in their drug release pattern (data not shown). HPMC showed better sustained release properties than a cassava starch and PVP as release retarding polymers. The cumulative percentage release of pantoprazole from the tablets varied from $65.0 \pm 0.2 \%$ to $98.7 \pm 0.1 \%$ after $12 \mathrm{~h}$ depending on the polymer and drug polymer ratio. F- 1 did not show any sustained release. This could be explained by the fact that F- 1 was prepared by omitting the release retarding polymer. For delayed release delivery systems, it was essential that the drug release would be minimal until the dosage form reached the intestine. To present drug release in the stomach, the tablets prepared were enteric coated (ECF3, ECF9 and ECF15) using CAP, Eudragit L100 and drug coat L100. None of the CAP coated tablets showed drug release during the first $2 \mathrm{~h}$ at acidic $\mathrm{pH} 1$ and drug release at $\mathrm{pH} 6.8$ took place in a sustained manner for a period of $12 \mathrm{~h}$. The dissolution profiles of ECF3, ECF9, and ECF15 (Fig. 1) demonstrated a pH dependent release mechanism. The cumulative percentage release of the drug from coated tablets ECF3, ECF9 and ECF15 varied from to $67.6 \pm 0.4 \%$ to $81.6 \pm 0.2 \%$.

Release kinetics. - The in vitro release data obtained from CAP coated tablets ECF3, Eudragit L100 coated tablets ECF9 and drug coat L100 coated tablets ECF15 were fitted to various kinetic models such as zero-order, first-order, Higuchi and Korsmeyer-Peppas models (11). The release of pantoprazole from the tablets was first-order diffusion controlled, as indicated by highest $R^{2}$ values (Table V). The $R^{2}$ value of the Higuchi model is

Table V. Release kinetics of formulations ECF3, ECF9 and ECF15 coated with CAP

\begin{tabular}{lccccc}
\hline Formulation & & \multicolumn{3}{c}{ Release kinetics $\left(R^{2}\right)$} & \\
& Zero-order & First-order & Higuchi & \multicolumn{2}{c}{ Korsmeyer-Peppas } \\
\cline { 5 - 6 } & & & & $R$ & $n$ \\
\hline ECF3 & 0.94 & 0.99 & 0.96 & 0.83 & 0.12 \\
ECF9 & 0.93 & 0.99 & 0.96 & 0.83 & 0.13 \\
ECF15 & 0.95 & 0.99 & 0.96 & 0.80 & 0.09 \\
\hline
\end{tabular}


B. Wilson et al.: Sustained release enteric coated tablets of pantoprazole: Formulation, in vitro and in vivo evaluation, Acta Pharm. 63 (2013) 131-140.

Table VI. Stability studies of the CAP coated tablet formulation ECF3

\begin{tabular}{|c|c|c|c|c|c|c|c|}
\hline \multirow{3}{*}{$\begin{array}{l}\text { Evaluation } \\
\text { parameter }\end{array}$} & \multicolumn{7}{|c|}{ Observation (days) } \\
\hline & \multirow[t]{2}{*}{ Initial } & \multicolumn{3}{|c|}{ Room temperature } & \multicolumn{3}{|c|}{$45^{\circ} \mathrm{C}(\mathrm{RH} 75 \%)$} \\
\hline & & 10 & 20 & 30 & 10 & 20 & 30 \\
\hline $\begin{array}{l}\text { Physical } \\
\text { appearance }\end{array}$ & $\begin{array}{l}\text { dark red } \\
\text { tablets }\end{array}$ & $\begin{array}{c}\text { no } \\
\text { change }\end{array}$ & $\begin{array}{c}\text { no } \\
\text { change }\end{array}$ & $\begin{array}{c}\text { no } \\
\text { change }\end{array}$ & $\begin{array}{c}\text { no } \\
\text { change }\end{array}$ & $\begin{array}{c}\text { no } \\
\text { change }\end{array}$ & $\begin{array}{c}\text { no } \\
\text { change }\end{array}$ \\
\hline $\begin{array}{l}\text { Average } \\
\text { mass }(\mathrm{g})^{\mathrm{a}}\end{array}$ & $0.205 \pm 0.027$ & $0.255 \pm 0.014$ & $0.256 \pm 0.035$ & $0.260 \pm 0.016$ & $0.257 \pm 0.018$ & $0.259 \pm 0.029$ & $0.262 \pm 0.035$ \\
\hline $\begin{array}{l}\text { Hardness } \\
\left(\mathrm{kg} \mathrm{cm}^{-2}\right)^{\mathrm{b}}\end{array}$ & $6.6 \pm 0.4$ & $6.5 \pm 0.1$ & $6.6 \pm 0.2$ & $6.6 \pm 0.1$ & $6.4 \pm 0.1$ & $6.4 \pm 0.2$ & $6.3 \pm 0.1$ \\
\hline $\begin{array}{l}\text { Drug } \\
\text { content }(\%)^{\mathrm{a}}\end{array}$ & $100 \pm 0.0$ & $99.54 \pm 0.1$ & $99.51 \pm 0.1$ & $99.4 \pm 0.1$ & $99.8 \pm 0.1$ & $99.47 \pm 0.1$ & $99.56 \pm 0.1$ \\
\hline $\mathrm{CDR}^{\mathrm{a}}(\%)$ & $87.7 \pm 0.1$ & $87.31 \pm 0.1$ & $87.43 \pm 0.2$ & $87.1 \pm 0.2$ & $87.1 \pm 0.4$ & $86.78 \pm 0.2$ & $86.5 \pm 0.5$ \\
\hline
\end{tabular}

$\mathrm{RH}$ - relative humidity

a Mean $\pm \mathrm{SD}, n=20$.

$\mathrm{b}$ Mean $\pm \mathrm{SD}, n=6$.

${ }^{\mathrm{c}}$ Mean $\pm \mathrm{SD}, n=3$.

$\mathrm{CDR}$ - cumulative drug released.

0.96 for all formulations. This indicates that the in vitro drug release data fit linearly to the Higuchi model. The $n$ value was $0.12,0.13$ and 0.09 for ECF3, ECF7 and ECF15, respectively. The $n$ value of the Korsmeyer-Peppas model was used to determine the mechanism of drug release from the dosage forms. All the cases the $n$ value was less than 0.5 indicating that the release mechanism was probably Fickian diffusion (11). The diffusion mechanism is further supported by high $R^{2}$ values in the Higuchi model (Table V).

Stability studies. - The stability study results of CAP tablets ECF3 are shown in Table VI. There were no significant changes in their physical appearance, average mass, hardness and drug content. The release profile did not show any significant changes either. Hence, it can be concluded that the developed tablets were stable and retained their pharmaceutical properties during a period of 1 month.

Animal studies. - The average ulcer score for the vehicle control group, stress control group and treated group was $15 \pm 2,97 \pm 3$ and $35 \pm 1$, respectively. The cellulose acetate phthalate coated tablet formulation ECF3 significantly reduced the incidence and severity of ulcer.

\section{CONCLUSIONS}

Designing a delayed release tablet with sustained release properties may avoid drug release in the acidic environment of the stomach. This may minimize fluctuations of drug level in blood, prolong therapeutic drug level in blood, improve drug efficacy and patient compliance. The enteric coated, especially CAP drug coated tablets, did not release the drug in the acidic $\mathrm{pH} 1.2$ for a period of $2 \mathrm{~h}$ and released the in the intestinal 
$\mathrm{pH}$ in a sustained manner. Preliminary animal studies revealed that cellulose acetate phthalate coated tablets markedly reduced the incidence of ulcer in comparison with the stress control groups, but it requires further studies as a drug delivery system.

\section{REFERENCES}

1. S. W. Hosking, S. C. S. Chung, M. Y. Yung, A. K. C. Li, J. J. Y. Sung, T. K. W. Ling and A. F. B. Cheng, Duodenal ulcer healing by eradication of Helicobacter pylori without anti-acid treatment: randomised controlled trial, Lancet 343 (1994) 508-510; DOI: 10.1016/S0140-6736(94)91460-5.

2. J. Weil, D. Colin-Jones, M. Langman, D. Lawson, M. Murphy, M. Rawlins, M. Vessey and P. Wainwright, Prophylactic aspirin and risk of peptic ulcer bleeding, Br. Med. J. 310 (1995) 827-830.

3. G. Sachs, Proton pump inhibitors and acid-related diseases, Pharmacotherapy 17 (1997) 22-37. DOI: 10.1002/j.1875-9114.1997.tb03675.x.

4. S. S. Ozturk, B. O. Palsson, B. Donohoe and J. B. Dressman, Kinetics of release from enteric-coated tablets, Pharm. Res. 5 (1988) 550-565; DOI: 10.1023/A:1015937912504.

5. Y. B. Huang, Y. H. Tsai, W. C. Yang, J. S. Chang, P. C. Wu and K. Takayama, Once-daily propranolol extended tablet dosage form: formulation design and in vitro/in vivo investigation. Eur. J. Pharm. Biopharm. 58 (2004) 607-614; DOI: 10.1016/j.ejpb.2004.03.037.

6. K. R. Reddy, S. Mutalik and S. Reddy, Once-daily sustained release matrix tablets of nicorandil: Formulation and in vitro evaluation, AAPS Pharm. Sci. Tech. 4 (2003) 480-488; DOI: 10.1208/pt040461.

7. B. Wilson, P. H. Sitarambhai, M. S. Sajeev and G. Vinothapooshan, Design and evaluation of sustained release matrix tablets of levofloxacin for effective treatment of microbial infection, Int. J. Drug Deliv. 3 (2011) 305-314.

8. Pharmacopoeia of India, Ministry of Health and Family Welfare, Government of India, Controller of Publications, New Delhi 1996, pp. A80-A84.

9. United States Pharmacopoiea 23, National Formulary 18, USP Convention, Rockville (MD) 1995, pp. 1328.

10. K. Tahara, K. Yamamoto and T. Nishihata, Application of model-independent and model analysis for the investigation of effect of drug solubility on its release rate from hydroxypropyl methylcellulose sustained release tablets, Int. J. Pharm. 133 (1996) 17-27; DOI: 10.1016/0378-5173(95)04400-0.

11. P. Costa and J. M. S. Lobo, Modeling and comparison of dissolution profiles, Eur. J. Pharm. Sci. 13 (2001) 123-133; DOI: 10.1016/S0928-0987(01)00095-1.

12. N. S. Parmar and J. K. Desai, A review of the current methodology for the evaluation of gastric and duodenal anti-ulcer agents, Indian. J. Pharmacol. 25 (1993) 120-135. 